\section{Por que a OMC é importante para o Brasil? Why is the WTO relevant to Brazil?}

\section{SANDRA MARIA CARREIRA POLÓNIA RIOS ${ }^{1}$ PEDRO DA MOTTA VEIGA ${ }^{2}$}

INTERNACIONAL

DOI: $10.12957 /$ rmi.2015.18438

Resumo: Esse artigo examina as principais tendências que orientam o processo de transformação a que vem sendo submetida governança do sistema multilateral de comércio, bem como os principais vetores de transformação na estrutura produtiva brasileira. A confluência das mudanças no contexto internacional e no ambiente doméstico exige uma atualização das políticas de inserção econômica internacional do Brasil. Tal atualização demandaria uma revisão das estratégias brasileiras nos foros de negociação da governança do comércio internacional, mas demanda também a adequação das políticas comercial e industrial domésticas aos da política econômica externa do país. Concluindo que o multilateralismo comercial continua tendo papel central na estratégia de inserção internacional do Brasil, o artigo apresenta sugestões de elementos para uma nova agenda do país na OMC.

Palavras-chave: Integração econômica; política comercial; negociações comerciais; organizações internacionais; política industrial.

Abstract: This article analyses the main driving forces that are shaping the undergoing transformation of the international trade system, as well as the main drivers of the structural transformations of the production structure in Brazil. The confluence of the changes in the international context and of the transformations at the domestic level demands the updating of the Brazilian international economic integration policies. This updating would demand the revision of the Brazilian strategies for the participation in the governance of the international trade system, but also the adjustment of the country's domestic trade and industrial policies. The article concludes that multilateralism continues to deserve a central role in Brazil's international integration strategy, and presents some suggestions for a new agenda for Brazil at the WTO.

Keywords: Economic integration; trade policy; trade negotiations; international organizations; industrial policy

\footnotetext{
${ }^{1}$ Diretora do Centro de Estudos de Integração e Desenvolvimento (CINDES), professora do Departamento de Economia da Pontifícia Universidade Católica do Rio de Janeiro (PUC-RJ) e consultora da Confederação Nacional da Indústria e membro do Conselho Superior da FUNCEX. E-mail: srios@ cindesbrasil.org

${ }^{2}$ Diretor do Centro de Estudos de Integração e Desenvolvimento (CINDES). Endereço para correspondência: Cindes - Rua Jardim Botânico, 635, sala 906 Rio de Janeiro. E-mail: mveiga@ cindesbrasil.org
} 


\section{Muralf INTERNACIONAL}

A Organização Mundial do Comércio (OMC) chega aos vinte anos sob a sombra da crise do multilateralismo comercial. As manifestações mais visíveis dessa crise são os impasses em que está imersa a Rodada Doha e o lançamento de negociações de megaacordos regionais de comércio, mas suas raízes encontram-se nas profundas transformações em curso na economia mundial e nos mecanismos de governança que regem as relações econômicas globais.

O multilateralismo é historicamente o foro negociador priorizado pelo Brasil na área comercial. Essa situação pouco se alterou no período (essencialmente os anos 90) em que a estratégia comercial brasileira sofreu a influência do Consenso de Washington e do "ciclo" do regionalismo aberto, que caracterizou a América Latina.

Na realidade, o país movimenta-se com dificuldade no mundo dos acordos regionais. Com os países desenvolvidos, os interesses demandantes brasileiros concentram-se nos temas que compõem o núcleo duro do protecionismo nesses mercados (agricultura). Ao mesmo tempo, o Brasil resiste a negociar regras e disciplinas em áreas que possam significar limitação de seu policy space doméstico, como proteção de investimentos, propriedade intelectual,
Mural Internacional

V. $6 \mid$ N. 1

JAN-JUN 2015 serviços e compras governamentais, que vêm sendo incorporadas na maioria dos acordos preferenciais recentes. Com os países em desenvolvimento, os acordos até hoje negociados foram pouquíssimos expressivos e refletem as dificuldades de superação dos conflitos de interesses nas agendas de comércio.

A primeira década do século XXI aumentou ainda mais o desequilíbrio entre os pesos do multilateralismo e do regionalismo, em favor do primeiro, na agenda comercial brasileira, mas a evolução recente das políticas econômicas no Brasil vem colocando o país em posição crescentemente defensiva na OMC. A crise do multilateralismo comercial é ruim para o Brasil, mas ao adotar instrumentos de política doméstica que desafiam as regras multilaterais o país termina por contribuir para o enfraquecimento da instituição que ocupa lugar de destaque em sua estratégia comercial.

\section{A mudança de contexto no cenário internacional e a OMC}

Não é apenas na área do comércio internacional que o multilateralismo passa por uma má fase: também no âmbito das negociações climáticas ou nas tentativas de reforçar a coordenação macroeconômica global, as dificuldades para se alcançar novos compromissos são evidentes. Embora muitos fatores 
possam ter contribuído para um ambiente internacional menos favorável ao multilateralismo, não resta dúvida de que a emergência de novos atores com interesses muito heterogêneos - mas com poder de influência para bloquear movimentos liderados de facto e de jure pelos EUA e pela União Europeia - tem tornado mais tortuoso o caminho do consenso na agenda das instituições que governam a ordem econômica mundial.

Essa evolução se faz presente nas negociações da Rodada Doha na OMC, em que o chamado Quad (grupo formado por Estados Unidos, União Europeia, Japão e Canadá), que costumava dar as cartas até o final da Rodada Uruguai, viu sua hegemonia contestada pelo ativismo de países emergentes como Brasil e Índia. O ingresso da China na OMC, em 2001, veio adicionar mais um elemento complicador ao já complexo ambiente em que as negociações são "costuradas".

Apesar de se ver questionada pela falta de progresso na negociação da Rodada Doha, em curso há 14 anos, e das ameaças vindas da possibilidade de que novos arranjos de comércio (os megaacordos como a Trans-Pacific Partnership - TPP - e a Transatlantic Trade and Investment Partnership TTIP) minem a sua relevância, a OMC tem serviços a mostrar em prol do comércio internacional. Talvez a maior prova de fogo para a OMC em duas décadas de existência tenha sido a travessia da crise financeira internacional instaurada em 2008.

Ao contrário do que muitos analistas temiam, a reação dos países à debacle dos mercados em 2008 não incluiu um forte recrudescimento do protecionismo comercial. Embora diversas medidas voltadas para o resgate de empresas e setores tenham sido adotadas em muitos países, não se observou um aumento generalizado de políticas protecionistas semelhante ao que havia ocorrido durante a Grande Depressão do período 1929-1933.

Ao contar com um amplo conjunto de regras comerciais que regem as relações de comércio de bens e serviços e incidem sobre a adoção de políticas domésticas que distorcem a competitividade, a OMC tem servido de balizamento para a contenção do protecionismo comercial. Esse arcabouço legal é acompanhado por um sistema de solução de controvérsias visto como um dos principais diferenciais entre a OMC e seu antecessor, o GATT - que, em boa medida, tem contribuído para dissuadir a adoção, pelos países membros, de práticas consideradas ilegais pelas 


\section{Muralf INTERNACIONAL}

regras da instituição. Em 20 anos, cerca de 500 disputas comerciais foram apreciadas pelo Mecanismo de Solução de Controvérsias da OMC.

Por fim, a duras penas, é verdade, foi concluído em dezembro de 2013 o primeiro acordo vinculante sob a égide da OMC - o Acordo de Facilitação de Comércio. Considerado uma espécie de early harvest da Rodada Doha, esse acordo incorpora compromissos voltados para a simplificação e desburocratização dos procedimentos aduaneiros. As dificuldades para a conclusão das negociações desse acordo, que não inclui medidas com impactos relevantes nas políticas comerciais e industriais dos paísesmembros, mostram como é limitado o campo para se avançar em compromissos em áreas mais sensíveis.

Novos vetores no comércio internacional e implicações para a regulação do comércio

Duas tendências que começaram a se consolidar em meados da primeira década do Século XXI e que se intensificaram nos últimos anos trazem novas implicações para o regime de comércio mundial e para as estratégias brasileiras nessa área.

A primeira delas vem pelo lado da oferta de bens e serviços e reflete a
Mural Internacional

V. $6 \mid$ N. 1

JAN-JUN 2015 evolução do processo de fragmentação da produção em âmbito mundial. Esse processo, que tem início nos anos 1960 , ganha novos contornos a partir da segunda metade dos anos 00, com a intensificação de movimentos de relocalização de atividades produtivas, consolidação de mercados, etc. Também fica mais claro, ao longo da evolução recente, o caráter regional ou megarregional da maioria dos arranjos produtivos nessa nova etapa da fragmentação da produção global.

No rastro desse processo vem uma agenda de políticas industriais $\mathrm{e}$ comerciais voltadas para favorecer $o$ funcionamento das cadeias de valor em âmbito global e regional. Essa agenda põe em relevo temas que, de algum modo, já faziam parte do menu das negociações de acordos de comércio, mas que agora ganham nova ênfase. Em particular, ganham atenção temas relacionados à convergência regulatória, liberalização do comércio de bens intermediários, reforço do respeito à propriedade intelectual e abertura ao comércio de serviços.

A segunda tendência vem pelo lado da demanda e pode ser entendida como consequência do crescente empoderamento do consumidor. Como disse Pascal Lamy, ex-Diretor Geral da 
OMC, em uma Conferência em 2014², "Overall, what is true is that the level of precaution will rise and this is inevitable. It is part of development. It is a logical consequence of people whose living standards are rising. This is what progress is about".

Essa tendência leva a uma crescente demanda por oportunidades de escolha, transparência nas informações sobre produtos e compromissos com princípios de precaução na fabricação de bens de consumo.

Como resultado, assiste-se a uma proliferação de normas e padrões privados relacionados à segurança de alimentos, saúde de plantas e animais, segurança energética, níveis de emissão de gases de efeito estufa no processo produtivo, cumprimento de regulações laborais e sociais, entre outros. As preferências dos consumidores quanto a esses padrões são influenciadas por valores culturais, daí resultando especificações diferentes para o mesmo produto de acordo com os mercados a que se destina. As regras da OMC dizem pouco sobre o tratamento a ser dado a padrões privados e sobre a possibilidade de que estes venham a

\footnotetext{
3 Pascal Lamy (2014) Future of WTO in a Multilpolar World.http://ccgi.fgv.br/sites/ccgi.fgv.br/files/file/Events/Mi nute\%20Lamy.pdf
}

constituir barreiras não-tarifárias ao comércio.

A conjunção das tendências pelo lado da oferta e da demanda no comércio internacional traz pressões adicionais sobre as regras do comércio internacional e sobre agenda da OMC. As implicações da evolução da fragmentação da produção estão relacionadas à: (i) "nova-velha" agenda temática das regras de comércio; (ii) maior demanda por arranjos regionais e megarregionais e (iii) ênfase na convergência regulatória e na redução de custos de transação.

Por sua vez as implicações do empoderamento do consumidor refletem-se na maior reação à convergência de normas e padrões técnicos, sanitários e fitossanitários, uma vez que os consumidores buscam a preservação de valores culturais e receiam o "nivelamento por baixo" que a convergência regulatória pode gerar. Como resultado, é provável que se tenha que lidar com um variado mix de regulamentos públicos e privados.

Em síntese, parece inescapável que o regime de comércio internacional tenha que conviver com arranjos que envolverão os âmbitos multilateral, megarregional, plurilateral e multilateral. Os países e atores buscarão negociar temas de seu interesse nos 


\section{Mural INTERNACIONAL}

foros que lhes permitam maior conforto para suas políticas domésticas, de um lado, e para a defesa dos interesses de suas empresas, de outro.

Para continuar sendo capaz de entregar novos acordos e compromissos em áreas que respondam às necessidades das empresas e às preferências dos consumidores, a OMC terá que atualizar sua agenda negociadora e seus mecanismos de governança. Entretanto, a organização tem como princípio fundamental o consenso como base de suas decisões. É uma organização members-driven e só será capaz de avançar se esse for o desejo comum de seus membros.

Não é por outro motivo que os arranjos megarregionais vêm ganhando espaço como alternativa de avançar em novas regras de comércio. Ao reunir países like-minded - ou seja, com visões convergentes em áreas de política relevantes para as negociações - essas iniciativas teriam maior facilidade de produzir consensos e alcançar acordos. Apesar de ser maior a probabilidade de que se avance mais rapidamente nesses foros, a experiência com o TPP, por exemplo, mostra que isso não é garantido. A conclusão das negociações vem sendo adiada por diversas vezes e os impasses persistem em torno da velha agenda de comércio: liberalização de
Mural Internacional

V. $6 \mid$ N. 1

JAN-JUN 2015 importações de produtos agrícolas, regras de origem, proteção para o setor automotivo, dentre outras.

\section{O Brasil nesse cenário fragmentado}

A prioridade que a OMC assume na agenda comercial brasileira é condicionada por características estruturais da economia do país e de suas preferências de política externa. A primeira característica está relacionada à distribuição setorial da produção e do comércio no Brasil: a relevância dos produtos agrícolas na pauta de exportações brasileiras e a existência de uma base industrial diversificada $\mathrm{e}$ verticalmente integrada, mas fundamentalmente voltada para o mercado doméstico, com poucos setores competitivos intensivos em tecnologia, como o de aeronaves.

Isso faz com que os interesses ofensivos brasileiros nas negociações comerciais concentrem-se em áreas que compõem o núcleo duro do protecionismo comercial de um grande número de países, desenvolvidos e em desenvolvimento. Se é possível buscar a redução ou eliminação de tarifas e quotas que incidem sobre produtos agrícolas em acordos regionais ou preferenciais, a negociação de subsídios agrícolas, principalmente os relacionados a medidas de apoio interno, tem a OMC como único foro disponível. 
De outro lado, o desejo de proteger o mercado interno e manter a base industrial diversificada e integrada verticalmente orienta as posições defensivas em todos os temas que possam representar estreitamento do espaço de políticas para proteger e estimular a produção doméstica. Também nesse sentido o foro multilateral é mais confortável para a política comercial brasileira, já que não tem como objetivo a completa eliminação de barreiras às importações e permite maximizar a barganha entre liberalização agrícola e para produtos industriais.

A segunda característica refere-se ao fato de o Brasil ser um pequeno ator global. $\mathrm{O}$ país tem pequena participação no comércio internacional, ocupando a $25^{\mathrm{a}}$ posição no ranking das exportações mundiais. Mas, embora pequeno, o país tem um comércio bastante diversificado regionalmente - as Américas representam $33 \%$ do comércio brasileiro, a União Europeia $20 \%$ e a Ásia 33\%. E, como já mencionado anteriormente, permanece à margem do mundo dos acordos preferenciais de comércio.

A dimensão política também é importante para explicar o lugar da OMC na agenda de negociações comerciais do Brasil. O componente político está relacionado ao grande apreço do país pelo multilateralismo e à sua aspiração pelo reconhecimento internacional, elemento central da política externa do Brasil. Este objetivo foi perseguido pela via de uma presença ativa nos fóruns multilaterais desde a segunda metade do século XX, quando surgiram os primeiros esforços de coordenação multilateral, inclusive na esfera comercial (criação do GATT). Essa aspiração ganhou novo fôlego com o protagonismo alcançado pelo Brasil na Rodada Doha e, de forma mais geral, com a emergência do país como ator relevante nas diferentes esferas de negociação econômica internacional.

with financing and tax incentives in the search for technological innovation. On the other hand, it is also possible to adopt a policy of negotiating preferential trade agreements with countries that complement such insertion, via reduction of tariffs, coordinated rules of origin, and importation of higher-tech components and technology transfer. Além das características estruturais, há elementos da dinâmica das transformações produtivas em curso no Brasil que devem estar presentes quando se discute as estratégias e a participação do Brasil na governança do comércio internacional. Os principais vetores da transformação produtiva no Brasil são o 


\section{Muralf INTERNACIONAL}

crescente peso dos setores intensivos em recursos naturais na economia brasileira e o mau desempenho da indústria de transformação, que perde rapidamente participação no PIB nacional.

Esses movimentos têm alimentado preocupações com o futuro da base produtiva no Brasil. $\mathrm{O}$ aprofundamento do processo de desindustrialização, em boa medida explicado pelo baixíssimo crescimento da produtividade da mãode-obra na última década, o forte crescimento dos custos sistêmicos, levando à perda de competitividade dos produtos nacionais, e a baixa participação das empresas brasileiras em cadeias globais de valor estão no centro dos debates sobre política econômica no país.

Ainda que as políticas industriais e comerciais adotadas pelo Brasil no póscrise tenham sido orientadas pelo objetivo central de neutralizar as transformações produtivas em curso no país, é provável que, em um horizonte de tempo mais longo, tais transformações terminem por consolidar, de fato, uma nova configuração da produção no país. Como resultado, é possível que se venha a ter uma indústria menos diversificada e menos integrada verticalmente, mas com alguns setores mais competitivos; segmentos de serviços mais eficientes e
Mural Internacional

V. $6 \mid$ N. 1

JAN-JUN 2015 com maior inserção internacional; e um maior número de empresas brasileiras com investimentos no exterior. Já na produção de alimentos o país tende a manter-se nas primeiras posições como fornecedor mundial.

A combinação de novos vetores que influenciam a governança do comércio mundial com as transformações em curso na estrutura produtiva brasileira coloca novos desafios para que o Brasil se movimente em um contexto internacional dominado pela fragmentação de processos produtivos, regras e foros de negociação. Entre esses desafios estão:

- A concentração das exportações brasileiras em produtos intensivos em recursos naturais, cada vez mais sensíveis a normas, padrões e regulamentos públicos e privados. A proliferação e a fragmentação na produção de regras e a existência de novos foros relevantes de negociação de tais regras e dos quais o Brasil não participa (TPP e TTIP) podem significar novas barreiras para as exportações brasileiras;

- O fato de o Brasil ser um dos mais competitivos produtores de alimentos do mundo. Temas como segurança alimentar e mudanças climáticas tendem a estar cada mais 
vez presentes nas negociações comerciais trazendo novas pressões sobre as políticas agrícolas e de proteção ambiental e suas relações com o comércio;

- A necessidade de atualizar a agenda de prioridades nas negociações comerciais, com parceiros já muito adiantados em termos de suas inserções em arranjos regionais e preferenciais. Caso a transformação produtiva na indústria de transformação leve a uma estrutura produtiva menos integrada verticalmente e mais integrada às cadeias globais de valor, a nova agenda temática relacionada ao processo de fragmentação do processo produtivo pode se tornar mais atraente para o país. Para tanto será importante para o país buscar uma participação mais ativa no mundo das negociações comerciais, após ter permanecido à margem desses movimentos enquanto esses evoluíam em várias dimensões;

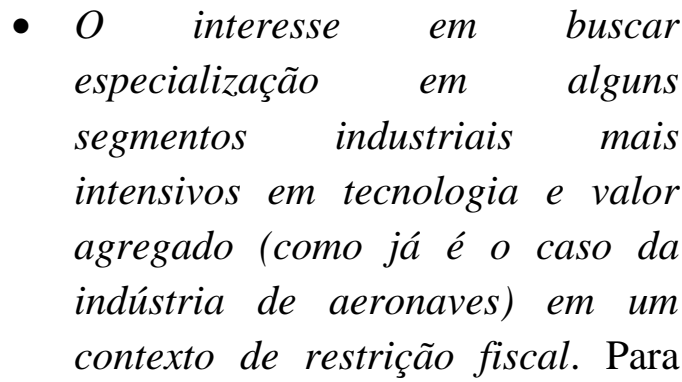

avançar nessa direção será preciso que o Brasil redesenhe suas políticas industriais e reveja suas posições quanto à agenda temática das negociações comerciais de que participa. Nessa transição, o país deverá dosar a conveniência de ter liberdade para adotar mecanismos de apoio ao desenvolvimento de segmentos industriais com o fato inescapável de que o país sofre persistente constrangimento fiscal para competir com subsídios oferecidos por outros países com maior capacidade fiscal.

\section{Elementos para uma nova agenda do Brasil na OMC}

Essa análise conflui para a conveniência de atualizar as estratégias do Brasil em termos de sua inserção nos foros de negociação da governança do comércio mundial, mas, ao mesmo tempo, reforça o papel prioritário do multilateralismo para o país. A especialização em setores intensivos em recursos naturais, a elevada competitividade na produção de alimentos e a busca por desenvolvimento de segmentos intensivos em tecnologia tornam a estrutura produtiva brasileira e suas exportações muito sensíveis às regras de comércio mundial.

Sendo um pequeno ator global, o Brasil tem tido um grau de influência nas 


\section{Muralf INTERNACIONAL}

negociações na OMC muito superior ao que seria esperado por sua participação no comércio mundial. Esse é um ativo importante para o país e que não pode ser desperdiçado. Até recentemente, o Brasil costumava pautar suas políticas industriais e comerciais pelo respeito aos compromissos assumidos no GATT e na OMC. Havia, na formulação das políticas domésticas, a preocupação com os limites estabelecidos pelas normas multilaterais, evitando o constrangimento de ser alvo de questionamentos no âmbito da organização. Esse comportamento levou a que o país fosse um dos grandes beneficiários do mecanismo de solução de controvérsias da OMC, sendo pouco acionado, mas utilizando o mecanismo para questionar políticas de outros países que distorcem a competitividade de seus produtos: os casos do algodão, açúcar e aeronaves tiveram grande repercussão.

No entanto, particularmente a partir do aprofundamento do processo de desindustrialização da economia brasileira, o país vem recorrendo com maior intensidade a políticas baseadas em conteúdo local. Essas políticas disseminaram-se por diversos setores industriais (automotivo, informática, telecomunicações, petróleo e gás, entre
Mural Internacional

V. $6 \mid$ N. 1

JAN-JUN 2015 outros) e terminaram por ser alvo de controvérsias na OMC. Há um painel estabelecido a pedido da União Europeia questionando uma vasta gama de políticas brasileiras e o Japão já manifestou interesse de abrir outra controvérsia questionando os mesmos programas.

As transformações em curso na estrutura produtiva brasileira e no contexto do comércio internacional oferecem uma oportunidade para que o Brasil promova uma revisão mais ampla de suas políticas domésticas e de suas estratégias para as negociações comerciais internacionais. As políticas industriais baseadas em conteúdo nacional não impediram que o processo de desindustrialização seguisse seu curso, mas geraram constrangimento na OMC para o país.

Se o multilateralismo tem papel central para a estratégia internacional do Brasil, o país precisa repensar sua contribuição para o fortalecimento da OMC. Além de rever suas políticas industriais e comerciais domésticas, é preciso rever suas posições na agenda negociadora da organização. O Brasil precisa fortalecer seu compromisso com o multilateralismo como instância de governança global e sua agenda deve traduzir este objetivo. 